\title{
Imposex in pre-pollution times. Is TBT to blame?
}

\author{
F. Garaventa ${ }^{\text {a }}$, M. Faimali ${ }^{\text {a }}$, A. Terlizzi ${ }^{b, *}$ \\ ${ }^{\text {a }}$ CNR - Institute of Marine Sciences, Section of Marine Technologies, Via de Marini, 6, 16149 Genova, Italy \\ ${ }^{\mathrm{b}}$ Department of Biological and Environmental Science and Technology, University of Lecce, CoNISMa, 73100 Lecce, Italy
}

More than 35 years ago, anomalous male traits in females of a gastropod species were reported as an expression of environmentally controlled sexual development (Blaber, 1970). This form of pseudohermaphroditism (Jenner, 1979) became famous as 'imposex' (Smith, 1971). It consists in a hormonal imbalance superimposing male characters, namely penis and vas deferens, on females' genitalia or, also, abnormal development of sexual traits in males. In extreme cases, females are sterilized by imposex, sometimes leading to population decline or to local extinction (Bryan et al., 1986). Imposex has now been reported for about 120 gastropod species worldwide. Evidence to date (Gibbs et al., 1987; Spooner et al., 1991) suggests that imposex is caused by tri-butyltin (TBT) compounds, contained in massively-used self-polishing antifouling paints, the most effective solution to prevent fouling on boat hulls (Terlizzi et al., 2001). Imposex is known to be induced by TBT at a very low ambient concentration, just a few nanogram per litre, and its development seems dose-dependent (Bryan et al., 1986). However, the causal, exclusive link between TBT and imposex still need to be assessed in all species where imposex has been reported, becoming one of the most controversial issues of marine biology in the last two decades. A search within article titles, keywords and abstracts of the term "Imposex" led to 350 articles published on ISI journals from 1986 to April 2006. Google scholar reports 1300 hits to the term and Google reaches 61300 hits. Imposex on gastropods is only one of the negative effects of TBT, others are mortality, monstruosities, and hormonal imbalance in dolphins, crabs, lobsters, oysters, invertebrate larvae, seagrasses, and algae (Evans, 1999 and references therein). Worldwide concern about TBT led many governments to limit TBT use, which at present is severely restricted or completely banned (Terlizzi et al., 2001). Levels of TBT in the marine environment, however, are still being monitored, to assess the effectiveness of the regulations and the possible chronic impact of this pollutant on marine biota. Despite remaining uncertainties, ecotoxicology still reports imposex as one of the few examples of specific response of organisms to a particular compound. Indices of imposex incidence have been developed and used as bioassay of TBT contamination in a large number of gastropods and in hundreds of biomonitoring programs. In most cases, surveys focused on impo-

\footnotetext{
* Corresponding author.

E-mail address: antonio.terlizzi@unile.it (A. Terlizzi).
}

sex assessments in new areas and/or new species, with the assumption that imposex occurrence is caused by TBT pollution. In contrast, even though there is little doubt that TBT has been the main cause of imposex in gastropods, it may be not the sole cause (Nias et al., 1993; Evans et al., 2000). Despite the widespread use of imposex as an index of TBT contamination, fundamental questions, such as what other factors may cause imposex, are still unanswered. Thus, environmental surveys are still guided by the paradigm of the exclusive relationship imposex-TBT (Terlizzi et al., 2004). Here we report evidence of imposex occurrence in gastropods prior to the use of TBT. TBTbased antifoulants first came on to the market in the 1960s but became widely used on ship hulls starting in the mid-1970s. We analyzed 55 museum $^{1}$ specimens of Hexaplex trunculus, a Mediterranean neogastropod species known as an exhibitor of imposex (Terlizzi et al., 1998). Samples had been collected between 1845 and 1930, 30115 years before the use of TBT, in several locations of Mediterranean Sea (Croatia, Italy, Tunisia and France) and Atlantic Portuguese coasts. Morphological inspection of specimens revealed anomalous male traits in four females as an incipient penis behind the right ocular tentacle and a bifallic male (Fig. 1).

Sex differentiation in many marine invertebrates is a plastic process that is under endocrine control. A suite of gastropod species reacts to TBT in a consistent way, disrupting neuroendocrine transmission, this response specifically affecting their morphogenetic patterns (e.g. Bettin et al., 1996). Our finding of imposex in specimens that lived before the TBT era challenge the TBT-imposex paradigm and is the clearest demonstration that factors other than TBT could alter the endocrine control of imposex development. These factors could range from exposure to heavy metals, to changes in environmental conditions (Nias et al., 1993), infestation by parasites (Gorbushin, 1997) and/or the influence of other androgenic compounds (Cajaraville et al., 2000). Experimentation towards an exhaustive understanding of the physiological mechanisms leading to imposex occurrence will unravel possible causal

\footnotetext{
${ }^{1}$ Muséum National d'Histoire Naturelle de Paris (Dr. Philippe Bouchet). Swedish Museum of Natural History (Dr. Anders Warén). Zoological Museum, University of Copenhagen (Dr. Ole Secher Tendal). Zoölogisch Museum, Universiteit van Amsterdam (Dr. Robert G. Moolenbeek). Museum für Naturkunde, Humboldt University, Berlin (Dr. Frank Koehler). Zoologisches Museum der Universitaet Hamburg (Dr. Bernhard Hausdorf).
} 

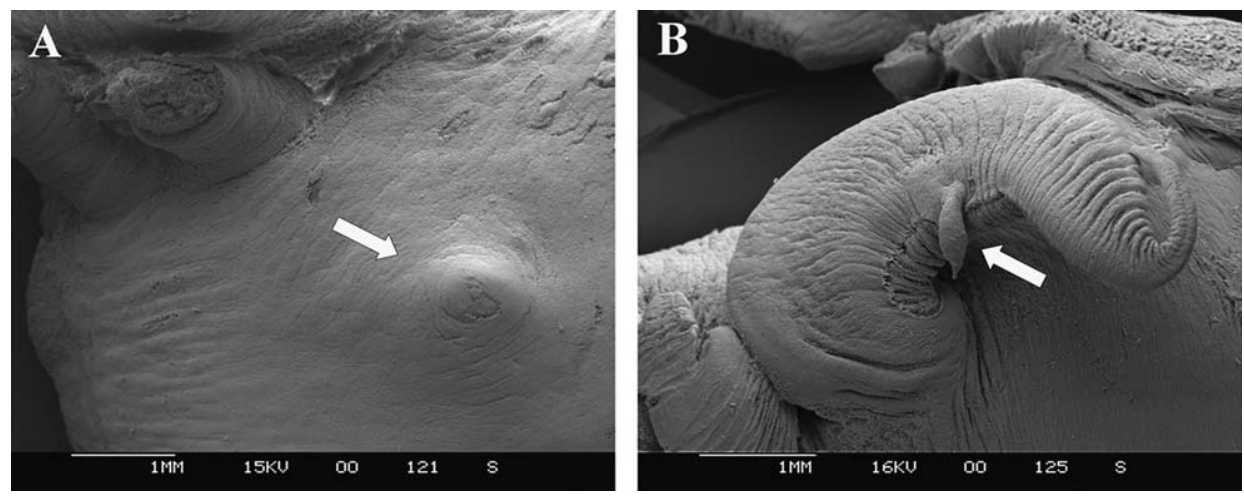

Fig. 1. Anomalous sexual traits in Hexaplex trunculus specimens: (A) a penial bump is visible in a female on the head, behind the right ocular tentacle (magnification: $16 \times$ ) and (B) a biphallic male (magnification: $20 \times$ ).

links, an issue that is crucial for future use of imposex in monitoring the effect of human pollution in coastal systems.

\section{Acknowledgements}

S. Schiaparelli and A. Sarà helped with the analyses of samples. The authors acknowledge the support by the MARBEF Network of Excellence "Marine Biodiversity and Ecosystem Functioning," which is funded in the Community's Sixth Framework Programme (contract no. GOCE-CT-2003-505446) and by NATO, Collaborative Linkage Grant No EST.CLG.979832.

\section{References}

Bettin, C., Oehlmann, J., Stroben, E., 1996. TBT-induced imposex in marine neogastropods is mediated by an increasing androgen level. Helgolander Meeresuntersuchungen 50, 299-317.

Blaber, S.J.M., 1970. The occurrence of a penis-like outgrowth behind the right tentacle in spent females of Nucella lapillus (L.). Proceedings of the Malacological Society of London 39, 231-232.

Bryan, G.W., Gibbs, P.E., Hummerstone, L.G., Burt, G.R., 1986. The decline of the gastropod Nucella lapillus around South-West England: evidence for the effect of trybutiltin from antifouling paints. Journal of the Marine Biological Association of the United Kingdom 66, 611640.

Cajaraville, M.P., Bebianno, M.J., Blasco, J., Porte, C., Sarasquete, C., Viarengo, A., 2000. The use of biomarker to assess the impact of pollution in coastal environments of Iberian Peninsula: a practical approach. The Science of the Total Environment 247, 295-311.

Evans, S.M., 1999. Tributyltin pollution: the catastrophe that never happened. Marine Pollution Bulletin 38, 629-636.

0025-326X/\$ - see front matter (c) 2006 Elsevier Ltd. All rights reserved. doi:10.1016/j.marpolbul.2006.02.018
Evans, S.M., Kerrigan, E., Palmer, N., 2000. Causes of imposex in the dogwhelk Nucella lapillus (L.) and its use as a biological indicator of tributyltin contamination. Marine Pollution Bulletin 40, 212219.

Gibbs, P.E., Bryan, G.W., Pascoe, P.L., Burt, G.R., 1987. The use of the dog-whelk, Nucella lapillus, as an indicator of tributyltin (TBT) contamination. Journal of the Marine Biological Association of the United Kingdom 67, 507-523.

Gorbushin, A.M., 1997. Field evidence of trematode-induced gigantism in Hydrobia spp. (Gastropoda: Prosobranchia). Journal of Marine Biology Association of the United Kingdom 77, 785-800.

Jenner, M.G., 1979. Pseudohermaphroditism in Ilyanassa obsoleta (Mollusca: Neogastropoda). Science 205, 1407-1409.

Nias, D.J., McKillup, S.C., Edyvane, K.S., 1993. Imposex in Lepsiella vinosa from Southern Australia. Marine Pollution Bulletin 26, 380 384.

Smith, B.S., 1971. Sexuality in the American mud snail, Nassarius obsoletus Say. Proceedings of the Malacological Society of London 39, 377-381.

Spooner, N., Gibbs, P.E., Bryan, G.W., Goad, L.J., 1991. The effect of tributyltin upon steroid titres in the female dogwhelk, Nucella lapillus, and the development of imposex. Marine Environmental Research 32, $37-49$.

Terlizzi, A., Delos, A.L., Garaventa, F., Faimali, M., Geraci, S., 2004 Limited effectiveness of Marine Protected Areas: imposex in Hexaplex trunculus (Gastropoda, Muricidae) populations from italian marine reserves. Marine Pollution Bulletin 48, 186-190.

Terlizzi, A., Fraschetti, S., Gianguzza, P., Faimali, M., Boero, F., 2001. Environmental impact of antifouling technologies: state of art and perspectives. Aquatic Conservation: Marine and Freshwater Ecosystems $11,311-317$.

Terlizzi, A., Geraci, S., Minganti, V., 1998. Tributyltin (TBT) pollution in the coastal waters of Italy as indicated by imposex in Hexaplex trunculus (Gastropoda, Muricidae). Marine Pollution Bulletin 36, 749 752. 